\title{
Graduates' Perspectives towards the Short-Term Internship and Its Impact on the Employability: Case Study of One Private University
}

\author{
Binazir Sankibayeva Sailaukyzy \\ Nazarbayev University
}

\begin{abstract}
In his recent address to the nation, President of Kazakhstan Nursultan Nazarbayev highlighted that the success of universities is determined by the number of graduates' who get rapid employment after finishing their studies. However, due to the lack of professional attributes, it is difficult for the graduates to get employed. Employers are reluctant to take inexperienced graduates and prefer those who have wide technical expertise. There is a lack of proper collaboration between industries and universities at the moment. Very little is known what experience Kazakhstani students gain during these profession-oriented internships. The current study is the product of the small-scale research that explores the impact of short-term internship on the employment of Kazakhstani graduates. Recent graduates of one private university have been interviewed and asked about their internship experience. The findings show that even though graduates of different specialties have been interviewed it has been found that the unsystematic design of the program left negative impressions among graduates. There is a discrepancy between the academic content and the market needs. As a result, some interviewees said that they had to learn everything from scratch when they started working. Other respondents became reluctant to pursue the job in their specialization. Further quantitative research needs to be carried out to better understand the specific factors that may impact on the students' WIL experience.
\end{abstract}

Keywords: cooperative education; work-integrated learning; career development; employability; work-based courses 